\title{
Comparing subpopulations of plasma progesterone using cluster analyses
}

\author{
S. Meier, ${ }^{* 1}$ J. R. Roche, ${ }^{*}$ E. S. Kolver, ${ }^{\star} \dagger$ G. A. Verkerk, ${ }^{*}$ and R. C. Boston $\ddagger$ \\ ${ }^{*}$ DairyNZ Limited, Private Bag 3221, Hamilton 3240, New Zealand \\ †Synlait, PO Box 9466, Hamilton, New Zealand \\ $\ddagger$ School of Veterinary Medicine, Kennett Square, University of Pennsylvania, New Bolton Center
}

\begin{abstract}
The production of progesterone during the luteal phase of the estrous cycle regulates early embryonic development, uterine function, and luteal function. Plasma progesterone concentrations were measured during a spontaneous estrous cycle in lactating Holstein-Friesian cows of New Zealand or North American ancestry, fed either fresh pasture or a total mixed ration. Subpopulations of profiles were identified using 2 approaches: 1 ) shape-based clustering and 2) trait-based clustering. Subpopulations of profiles were compared using key progesterone profile components, which described the early and late luteal phase of the estrous cycle. The application of resistant nonlinear smoothing functions across raw progesterone profiles resulted in a high degree of agreement between the raw data and smoothed estimates $\left(R^{2}=0.93\right)$. Both clustering techniques resulted in the identification of 3 similar subpopulations of progesterone profiles. The distribution of animals in these defined subpopulations and the association with cow strain and diet were examined. The early luteal phase was similar for the shape-based categories, but differed in the trait-based analyses. Differences in the late luteal phase and the onset of functional luteal regression in the different clusters were evident for both the shape- and trait-based analyses. The distribution of animals across the subpopulations identified by shapebased clustering was not associated with either cow strain or diet. However, within the 3 subpopulations identified using trait-based clustering, cow strain affected the shape of the progesterone profile. Isolation of 3 subpopulations within a small data set showed that otherwise normal progesterone profiles exhibit significant variation. The differences in the luteal phase of these subpopulations, in particular progesterone early in the luteal phase and the early onset of functional luteal regression, may provide an insight into factors associated with subfertility.
\end{abstract}

Key words: resistant nonlinear smoothing, progesterone, luteal phase, bovine

Received June 17, 2008.

Accepted November 4, 2008.

${ }^{1}$ Corresponding author: Susanne.Meier@DairyNZ.co.nz

\section{INTRODUCTION}

Progesterone is important for reproductive success, enhancing early embryonic growth, modifying the uterine environment, and ensuring adequate uterine receptivity (Spencer and Bazer, 2002; Inskeep, 2004). Elevated plasma progesterone concentrations between d 5 and 7 of the estrous cycle have been associated with larger embryos (Mann and Lamming, 2001) and improved conception rates (Stronge et al., 2005; McNeill et al., 2006), possibly a result of increased interferon-tau production by the larger embryos (Silvia et al., 1991; Geisert et al., 1992). Progesterone is also one of several hormones indirectly regulating the timing of luteal regression (Okuda et al., 2002), an important variable in ensuring reproductive success.

Nutritional status, the extent and duration of early lactation negative energy balance, and change in BCS have all been implicated as indicators of fertility status (Beam and Butler, 1999; Buckley et al., 2003; Roche et al., 2007a). Follicle growth, luteal function, and progesterone clearance can be modified by DMI, which in turn can alter progesterone concentrations (Wathes et al., 2003; Wiltbank et al., 2006). However, there is little information on the effect of genetic strain and feeding system (e.g., grazed pasture or TMR) on either progesterone concentrations or the shape of the progesterone profile.

Using mathematical functions and data smoothing to describe plasma progesterone concentrations minimizes random variation while simultaneously capturing the profile of interest and exposing distinct parameters that quantify biological function and processes. A recent study outlined the development of a model using smoothed milk progesterone profiles to predict reproductive status in dairy cows (Friggens and Chagunda, 2005), verifying the usefulness of smoothing techniques in the examination of these types of data. Using smoothing and clustering techniques to group similar profiles, the main objectives of the current study were to identify subpopulations of progesterone profiles within a data set of normal estrous cycles, to characterize differences in luteal function across these subpopulations. In addition, the association of cow strain and diet with each profile shape was tested. 


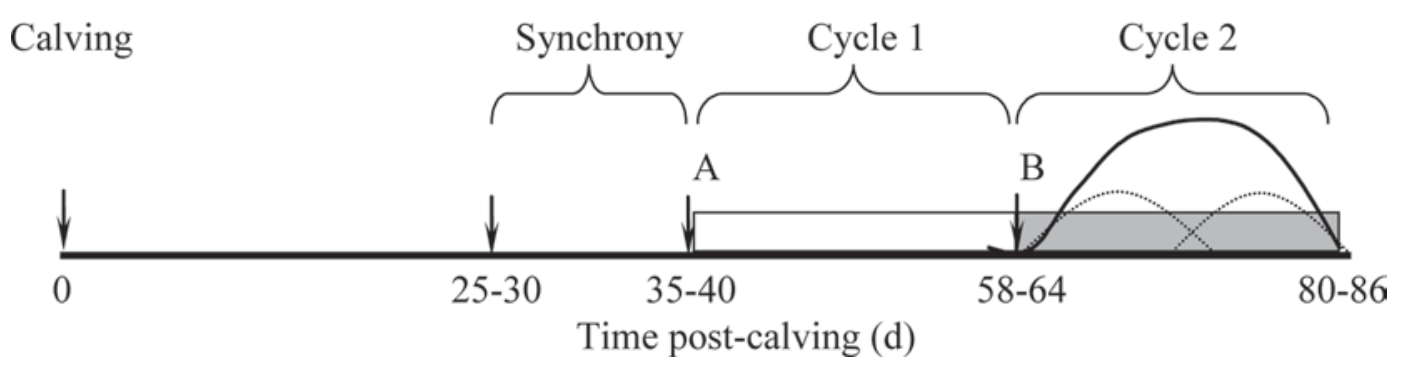

Figure 1. Experimental timeline from calving through to the estrous cycle used for the current analysis (cycle 2). Days postcalving represent the range of days postcalving for each event. A) Ovulation resulting from synchrony and B) spontaneous ovulation.

\section{MATERIALS AND METHODS}

\section{Experimental Data}

Animals and Diets. The experimental manipulations described were carried out with the approval of the Ruakura Animal Ethics Committee (Hamilton, New Zealand). This study was a No. 1 Dairy (Hamilton, New Zealand) as part of a larger multi-lactational study (Kolver et al., 2002).

Two strains of Holstein-Friesian cows of either North American $(>87.5 \%$ NA) or New Zealand $(<12.5 \%$ $\mathrm{NA}$; NZ) origin were used. The origins of cow sires are provided in more detail by Kolver et al. (2002). Dietary treatments consisted of either fresh pasture (FP) grazed in an intensive rotational manner, similar to that described by Roche et al. (2006), or a TMR, as described by Kolver et al. (2002). Cows within strain were randomly allocated to feeding system, resulting in a $2 \times 2$ factorial arrangement with 14 cows in the NZFP, 13 cows in NA-FP, 14 cows in the NZ-TMR, and 14 cows in the NA-TMR groups, respectively (Kolver et al., 2002).

The experimental design was described in detail by Kolver et al. (2002). Briefly, cows of NZ and NA origin were maintained as separate herds within feeding system. Cows fed FP were generously fed throughout lactation (i.e., pasture allowance of $>60 \mathrm{~kg}$ of $\mathrm{DM} / \mathrm{cow}$ per day was offered to ground level). Pasture grazing residuals were used to determine pasture allocation: post-grazing residuals of greater than $1,800 \mathrm{~kg}$ of $\mathrm{DM}$ per ha were targeted during spring and autumn and greater than 2,200 $\mathrm{kg}$ of DM per ha during summer. Cows fed TMR were confined to a loafing paddock or a free-draining feed-pad. The TMR ration was formulated to supply nutrients to maximize milk production (National Research Council, 2001) and is detailed by Kolver et al. (2002).

Animal Manipulations and Blood Sampling. Animals were grouped by calving date to ensure management of events was consistent relative to time postcalving across all cows. The estrous cycles of the animals were synchronized at 25 to $30 \mathrm{~d}$ postcalving, using a controlled intravaginal drug-release device (CIDR) containing $1.38 \mathrm{~g}$ of progesterone (CIDR-B, Pfizer Animal Health, Auckland, New Zealand) for 8 $\mathrm{d}$ and an intramuscular injection of $10 \mu \mathrm{g}$ of a $\mathrm{GnRH}$ analog (buserelin; Receptal, Intervet Ltd., Auckland, New Zealand) on the day of device insertion. All animals received $\mathrm{PGF}_{2 \alpha}$ (25 $\mathrm{mg}$ of dinoprost; Lutalyse, Pfizer Animal Health) on the day before CIDR withdrawal and $1 \mathrm{mg}$ of estradiol benzoate (CIDIROL, Bomac Laboratories Ltd., Auckland, New Zealand) $24 \mathrm{~h}$ after CIDR withdrawal. All animals completed one spontaneous estrous cycle following synchronization. The second estrous cycle, which resulted from a spontaneous ovulation, was the estrous cycle reported in this study. A timeline of the experimental events is provided in Figure 1.

Ovarian structures were examined daily between 0800 $\mathrm{h}$ and $1000 \mathrm{~h}$ by transrectal ultrasonography using a 7.5-MHz linear array transducer (Aloka DX210, Medtel, Auckland, New Zealand), starting $17 \mathrm{~d}$ after synchronized estrus. Luteal and follicle growth were monitored to calculate the number of follicular waves during the estrous cycle. Blood samples were collected daily from the coccygeal vein into evacuated tubes (Vacutainer, Becton, Dickinson and Company, Franklin Lakes, NJ) containing sodium heparin, immediately placed in ice water and centrifuged within $2 \mathrm{~h}(15 \mathrm{~min}$ at $1,500 \times g)$. Aspirated plasma fractions were stored at $-20^{\circ} \mathrm{C}$.

Progesterone Assay. Plasma progesterone concentrations were determined using a commercial RIA (Coat-A-Count, Diagnostic Products Corp., Los Angeles, CA). This assay has been previously validated for use in cattle (McDougall et al., 1995). The intraassay coefficients of variation at concentrations of 4.3, 3.1, and $0.4 \mathrm{ng} / \mathrm{mL}$ were $4.8,5.9$, and $13.4 \%$, respectively. The sensitivity of the assay was $0.1 \mathrm{ng} / \mathrm{mL}$.

\section{Smoothing and Clustering Techniques}

Resistant nonlinear smoothing methods were used to assist with the separation of true plasma progesterone profiles from aberrant spikes and troughs in the raw 
Table 1. Difference in luteal phase components between raw and smoothed progesterone profiles (mean $\pm \mathrm{SE})^{1}$

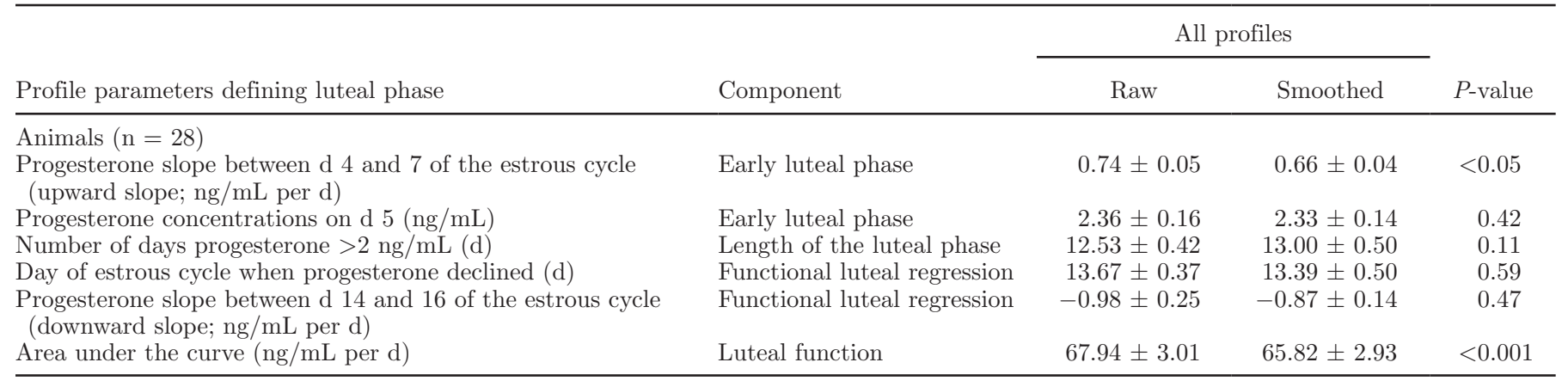

${ }^{1} \mathrm{R}^{2}$ and the linear association of the smoothed and raw progesterone values equaled to 0.93 (ranging from of 0.87 to 0.98 ).

observations (Gould, 1993; Salgado-Ugarte and Curtis, 1993). Two alternative approaches were investigated to separate the study population into common groups (or clusters): 1) shape-based clustering and 2) trait-based clustering. Both approaches closely follow the methodology of Everitt et al. (2001) and Rabe-Hesketh and Everitt (2004).

For shape-based clustering, the progesterone profile data were scaled and submitted to hierarchical agglomerative clustering, using the average linkage procedure. In comparison, trait-based clustering used agglomerative hierarchical techniques applied to a subset of empirical features using Ward's linkage procedure. These empirical features were different from the profile components used to compare the luteal phase of the estrous cycle (outlined below). Empirical profile features included: 1) peak progesterone concentration following smoothing, 2) day at which peak progesterone concentration following smoothing occurred, 3) slope of smoothed progesterone at the day of peak for the raw progesterone concentrations, 4) upward slope of the smoothed progesterone for days $>10$ of the estrous cycle, 5) downward slope of smoothed progesterone for days $>15$ of the estrous cycle, 6) minimum curvature of smoothed progesterone profile, and 7) day at which minimum curvature occurred. The profile features differed from the profile components used to compare the subpopulations of progesterone profiles (as outlined below). Rules for selection of the linkage procedure, including when to stop and the finally accepted number of groups, were based on those outlined by Everitt et al. (2001) and Rabe-Hesketh and Everitt (2004).

The comparison of smoothed and raw progesterone concentrations by cow gave $\mathrm{R}^{2}=0.93$, ranging from of 0.87 to 0.98 . A comparison of raw and smoothed progesterone profiles of the 3 shape-based and 3 trait-based clusters revealed no effect of smoothing on all but one of the luteal phase components examined. Smoothing reduced $(P<0.05)$ the slope of progesterone between d 4 and 7 of the estrous cycle (raw: $0.74 \pm 0.05 \mathrm{ng} / \mathrm{mL}$ per day, and smoothed: $0.66 \pm 0.04 \mathrm{ng} / \mathrm{mL}$ per day); however, average progesterone on $\mathrm{d} 5$ of the estrous cycle was not different $(P=0.42)$. Total progesterone release (calculated as area-under-the-curve, AUC) was less in the smoothed profiles compared with the raw profiles for the 3 shape-based clusters (Table 1) and trait-based clusters (data not shown).

\section{Comparisons of Subpopulations of Progesterone Profiles}

The identified shape- and trait-based clusters were compared through different stages of the luteal phase of the estrous cycle (Figure 2). These included 2 components that defined the early luteal phase of the progesterone profile: 1) the slope of progesterone between $\mathrm{d} 4$ and 7 of the estrous cycle (upward slope) and, 2) average progesterone on $\mathrm{d} 5$ of the estrous cycle. Progesterone concentrations through the entire estrous cycle were compared using total progesterone (AUC), and the length of the luteal phase was determined as the days progesterone concentrations were $>2 \mathrm{ng} / \mathrm{mL}$. The onset of luteal regression was determined as the day progesterone began to decline, with the slope of progesterone concentrations from d 14 to 16 of the estrous cycle (downward slope) taken as a measure of functional luteal regression. These components described specific areas of the progesterone profile that have been associated with reproductive performance.

\section{Statistics}

Means for BW and 4\% FCM yield were calculated for the 3 -wk period starting from d 0 of the experimental estrous cycle, and total milk yield for the lactation were analyzed using linear models, with feeding system (FP or TMR) and genetic strain (NZ or NA) as fixed effects (GenStat Release 6.1; VSN International Ltd., Hemel Hempstead, UK).

Luteal phase components were estimated for each defined cluster from the 2 grouping procedures and for 


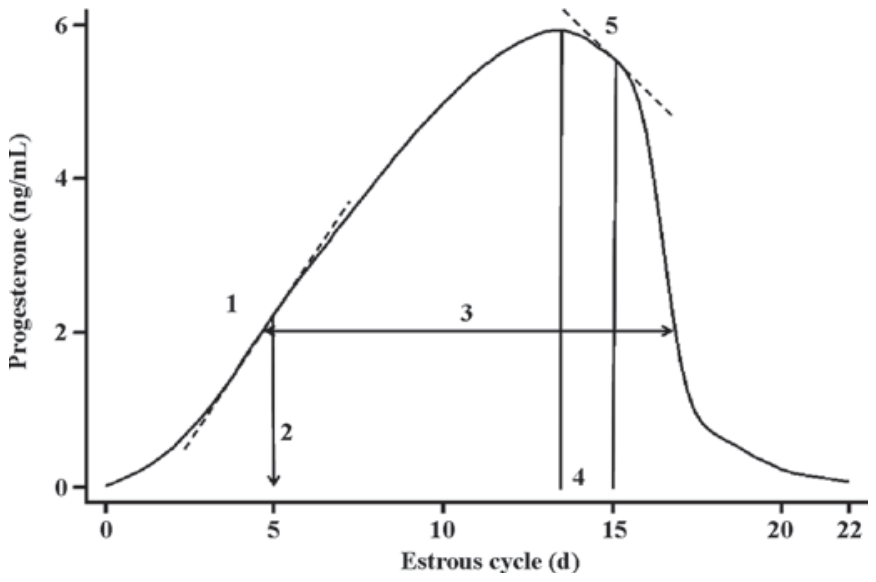

Figure 2. Luteal phase components used to compare progesterone profile subpopulations identified using the shape-based and trait-based clusters: 1) progesterone slope between d 4 and 7 of the estrous cycle (upward slope; $\mathrm{ng} / \mathrm{mL}$ per $\mathrm{d}$ ), 2) progesterone concentrations on $\mathrm{d} 5$ (ng/mL), 3) number of days progesterone $>2 \mathrm{ng} / \mathrm{mL}(\mathrm{d}), 4$ ) day of estrous cycle when progesterone declined (d), 5) progesterone slope between d 14 and 16 of the estrous cycle (downward slope; ng/mL per d), and 6) total progesterone release as the area-under-the-curve (AUC).

both the smoothed and raw profiles for each grouping. Both parametric (paired and unpaired $t$-tests) and non-parametric (sign-rank and Kruskal-Wallis) tests were used to determined whether the luteal phase components differed across groups or whether raw versus smooth bases for estimation of the luteal phase components differed. A Bonferroni correction was applied where multiple ranges were involved. Tests of association causing progesterone profile, diet, and genetic strain for each of the clustering procedures were performed using Fisher's exact test. The statistical investigations presented, including resistant nonlinear smoothing, cluster analysis, regression analysis, tests for normality, univariate hypothesis tests, and the analysis of tabular associations (Fisher's test) were performed using Stata 9.2 (StataCorp, College Station, TX). A $P$-value of 0.05 was used to indicate significant differences, unless otherwise stated. Where strain $\times$ diet interactions were not significant, main effects are presented.

\section{RESULTS}

\section{Animals}

Twenty-eight cows underwent a spontaneous ovulation, completing a normal estrous cycle between 18 and $24 \mathrm{~d}$ in length (Figure 3 ). Eligible animals included 15 $\mathrm{NZ}$ cows and $13 \mathrm{NA}$ cows, $13 \mathrm{FP}$ cows and $15 \mathrm{TMR}$ cows (NZ-FP $\mathrm{n}=6$, NZ-TMR $\mathrm{n}=9$, NA-FP $\mathrm{n}=7$, NATMR $\mathrm{n}=6)$. As reported previously, all estrous cycles consisted of 2 waves of follicular growth (Fahey et al., 2003). Of the cows excluded, 5 cows were late calving, 17 cows did not respond to the initial synchrony, 4 cows
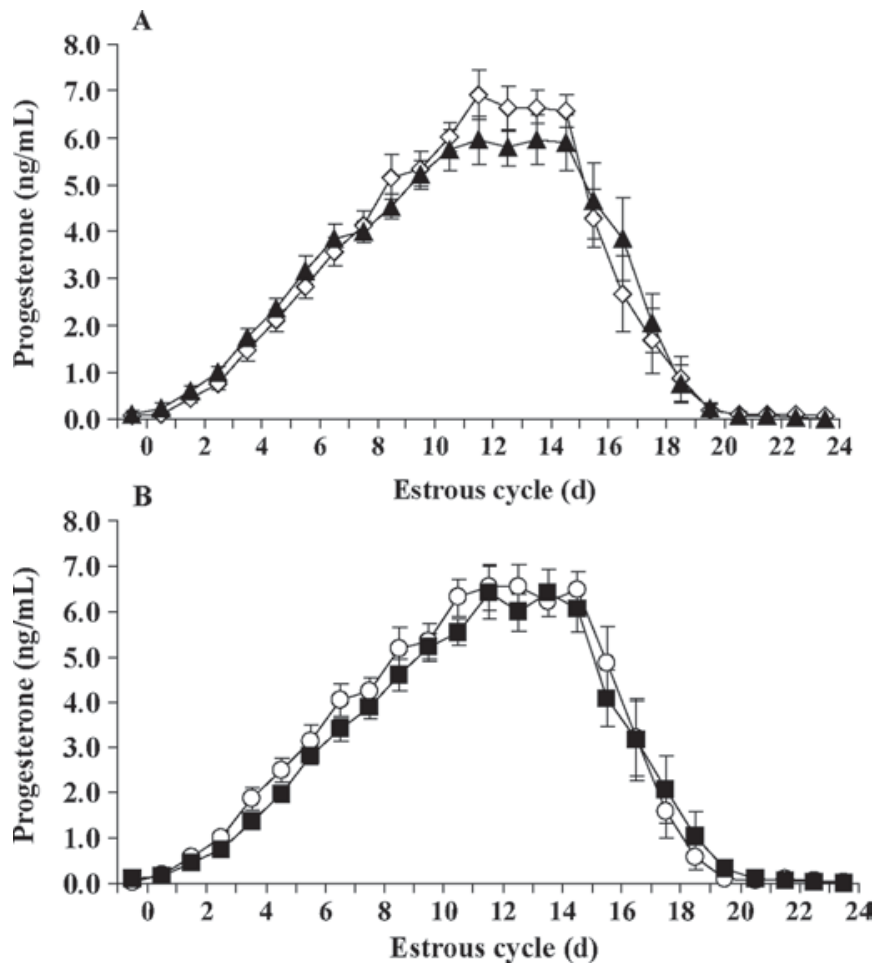

Figure 3. Raw plasma progesterone concentrations in: A) New Zealand $(\diamond ; \mathrm{n}=15)$ and North American Holstein-Friesian cows $(\boldsymbol{\Delta} ; \mathrm{n}$ $=13)$, and $\mathrm{B})$ fresh pasture-fed $(O ; \mathrm{n}=13)$ and TMR-fed cows $(\mathbf{\square}, \mathrm{n}$ $=15$ ) undergoing a normal spontaneous estrous cycle. Day 0 is the day of estrus. Error bars represent the standard error of the mean (SEM).

had extended estrous cycles ( $>27 \mathrm{~d})$, and 1 cow had to be removed due to a severe metabolic disorder.

The experimental estrous cycle began at $63 \pm 4.2$ DIM (mean \pm SE). Average parity was similar for the $\mathrm{NZ}$ and NA cows at $2.8 \pm 1.08$, with the FP-fed $(3.5$ $\pm 1.08)$ tending to be older than TMR-fed $(2.5 \pm 1.08)$ cows. Average BW was compared during three 7-d periods following the spontaneous estrus. During these periods, NZ cows were lighter $(P<0.05)$ than NA cows $(509 \pm 7.0 \mathrm{~kg}$ and $579 \pm 7.0 \mathrm{~kg}$, respectively) and cows grazing FP were lighter $(P<0.01)$ than TMR-fed cows $(501 \pm 7.0 \mathrm{~kg}$, and $577 \pm 7.0 \mathrm{~kg}$, respectively).

Lactation length was similar across strain (NZ $281 \pm$ 8.7 DIM and NA: $270 \pm 8.7$ DIM) and diets (FP $270 \pm$ 8.7 DIM and TMR $281 \pm 8.7$ DIM). Annual milk yield (4\% FCM) was not affected by genetic strain $(6,618 \mathrm{~kg} /$ cow and $6,800 \pm 584.9 \mathrm{~kg} /$ cow for NZ and NA cows, respectively; SE $584.9 \mathrm{~kg} /$ cow). In comparison, FP-fed cows produced less $(P<0.05)$ milk than TMR-fed cows $(5,693 \mathrm{~kg} / \mathrm{cow}$ and $7,578 \mathrm{~kg} / \mathrm{cow}$, respectively; SED $584.9 \mathrm{~kg} / \mathrm{cow})$, respectively. Average milk production (4\% FCM) during the 3 -wk period of the estrous cycle was similar $(P=0.78)$ for NZ $(29.9 \pm 0.58 \mathrm{~kg} /$ cow per d) and NA cows $(30.6 \pm 0.65 \mathrm{~kg} /$ cow per d), but was greater $(P<0.05)$ in TMR-fed cows when compared 


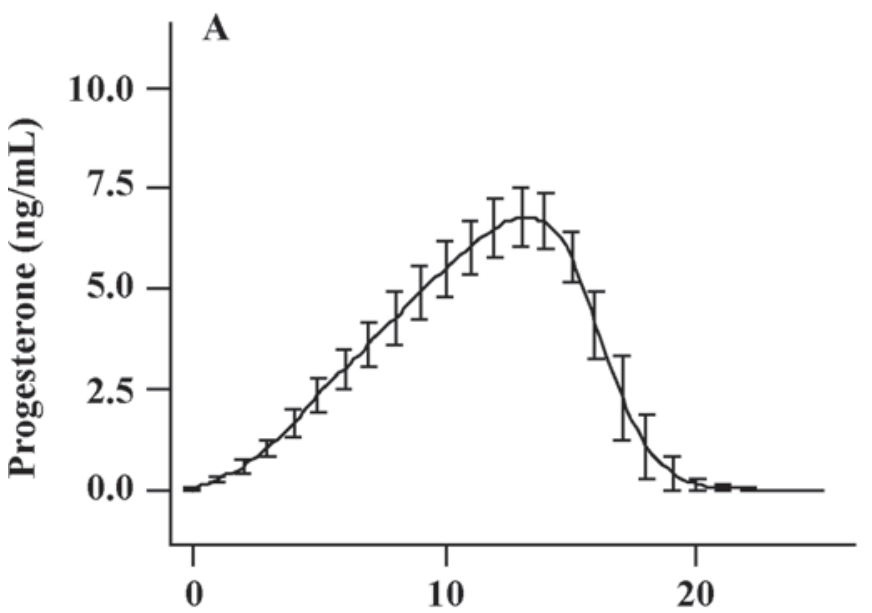

Estrous cycle (d)
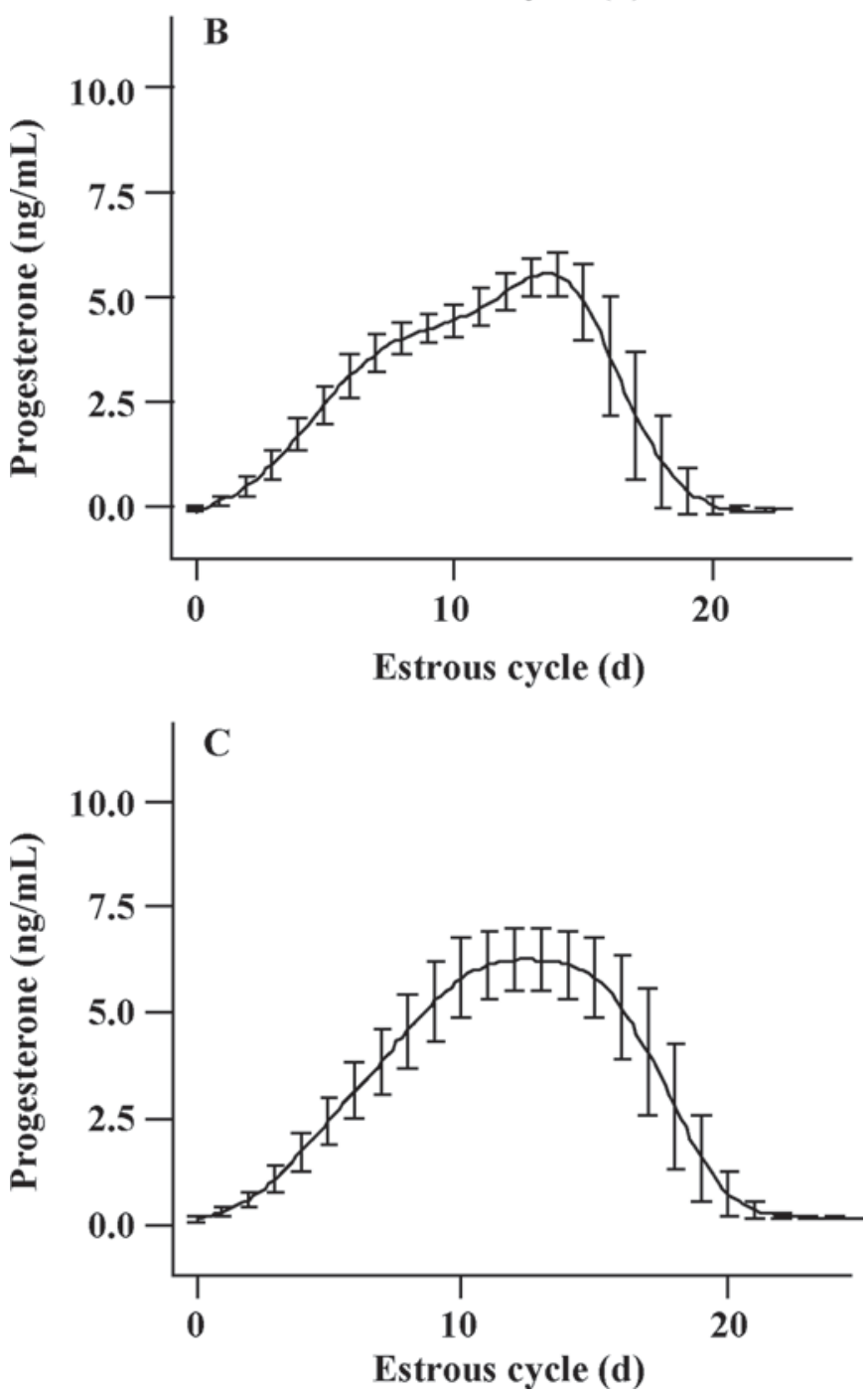

Figure 4. Scaled progesterone profiles for each of the subpopulations identified using shape-based clustering: A) peaked profile, B) structured profile, and C) flat top profile. with FP-fed cows $(33.2 \pm 0.58 \mathrm{~kg} /$ cow per d and $26.8 \pm$ $0.66 \mathrm{~kg} /$ cow per d, respectively). There was no interaction between genetic strain and feeding system.

\section{Shape-Based Clustering}

Average scaled progesterone profiles for each of the 3 shape-based clusters were defined as either peaked profile (Figure 4A), with the profile reaching a distinguishable peak, structured (Figure 4B), with the profile exhibiting a wave-like pattern, or flat top (Figure 4C), with the profile reaching a plateau. Distributions were 13,7 , and 7 cows exhibiting a peaked, structured, or flat top profile, respectively. The progesterone profile from 1 cow was unsuitable for analysis using the shape-based techniques and therefore removed from the analyses using the shape-based clustering.

Of the luteal phase components examined (Table 2), there were no differences between the 3 shape-based clusters for either upward slope between d 5 to 7 of the estrous cycle, average plasma progesterone concentrations on $\mathrm{d} 5$ of the estrous cycle, or the day of progesterone decline. The days plasma progesterone concentrations were $>2 \mathrm{ng} / \mathrm{ml}$ were greater in flat top profiles compared with peaked profiles, but not different from the structured profiles. The downward progesterone slope was greater for peaked profiles than structured profile, which in turn was greater than flat top profiles. The downward slope between d 14 to 16 of the estrous cycle was greatest for the peaked profile, followed by structured, and flat top profiles. Total progesterone released (AUC) was greater for the flat top profile compared with peaked profiles, but similar to structured profiles.

There was no association between progesterone profile shape and genetic strain $(P=0.39)$; peaked (NZ 9; NA 4), structured (NZ 3; NA 4) and flat top (NZ 3; NA 4). Similarly, there was no apparent relationship ( $P$ $=0.85$ ) between diet and progesterone profiles; peaked (FP 6; TMR 7), structured (FP 4; TMR 3), and flat top (FP 3; TMR 4).

\section{Trait-Based Clustering}

Mean progesterone shapes for each of the 3 traitbased clusters are presented in Figure 5 and luteal phase components are compared in Table 3. The distribution of the 28 cows into the trait-based clusters was 12 cows in cluster 1,4 cows in cluster 2 , and 12 cows in cluster 3 . There was no difference between the 3 trait-based clusters for the upward slope or days progesterone $>2 \mathrm{ng} / \mathrm{mL}$ (Table 3 ). The cluster 3 profile had lower progesterone levels on d 5 of the estrous cycle compared with cluster 2, but was similar to cluster 1 . 
Plasma progesterone on $\mathrm{d} 5$ of the estrous cycle was not different between cluster 1 and cluster 2. The day of progesterone decline occurred earlier in cluster 2 compared with cluster 1 and cluster 3 . The downward slope (d 14-16) was significantly steeper for cluster 1 than either cluster 2 or cluster 3, which did not differ from each other. Total progesterone release (AUC) was greater for cluster 2 when compared with cluster 1 and cluster 3 .

An association $(P<0.05)$ between strain and clusters was observed with cluster 1 and 2 having more NZ cows and cluster 3 having more NA cows: cluster 1 (NZ 8; NA 4), cluster 2 (NZ 4; NA 0) and cluster 3 (NZ 3; NA 9). There was no evident relationship $(P=0.67)$ between feeding system and the distribution of animals into the different profiles (cluster 1, 2, or 3 ).

\section{DISCUSSION}

The results from the current study indicate that subpopulations of progesterone profiles can be isolated within a small data set of otherwise normal progesterone profiles. Differences in the luteal phase of these subpopulations, in particular progesterone early in the luteal phase and the early onset of functional luteal regression, between these subpopulations may provide an insight into factors associated with subfertility. The advantages of the current analyses were that the database included only estrous cycles of normal length. Variability in estrous cycle length was further reduced with all cycles consisting of 2 waves of follicular growth. Therefore, the identification of profile subpopulations were achieved within very specific criteria, and were not affected by abnormal estrous cycles (Royal et al., 2000; McCoy et al., 2006; Petersson et al., 2006).

The smoothing and cluster analysis techniques reduced the variation within the data set, enabling subpopulations of profiles to be identified by shape characteristics. As a generic method, cluster analysis aims to uncover groups or clusters of individuals that are homogeneous and separate, and have been used to examine medical data (Jones et al., 2002) and to separate clusters of dairy cows exhibiting different profiles of BCS change (Roche et al., 2007b). Both of these techniques were robust, as only one estrous cycle could not be analyzed, with a large concordance $\left(\mathrm{R}^{2}=\right.$ 0.93 ) between raw and smoothed progesterone profiles. Despite the positive attributes of these techniques, loss of data needs to be expected when smoothing (as seen with the progesterone slope on d 4 to 7 of the estrous cycle and total progesterone release; AUC). However, smoothing had little impact on the remaining luteal phase components used to compare across the subpopulations identified. Therefore, the results indicate 
that smoothing and clustering techniques are valid approaches to identify and characterize subpopulations of progesterone profiles.

Three distinct profiles were isolated using the 2 different clustering techniques. The similarity in the shape of these clusters, despite their independent origin, provides strong evidence of differently shaped progesterone profiles in a seemingly normal estrous cycle. Although profile shapes were similar between the shape and trait clustering, the distribution of cows into these clusters was subtly different, and this seemed to be due to the distribution of cows in the structured and the flat-top shaped profiles in particular.

Two of the subpopulations of progesterone profiles identified in this study were characterized with an early onset of functional luteal regression (the decline in plasma progesterone concentrations; peaked and cluster 2 cows) compared with the other subpopulations. Such subtle differences in the progesterone profile during the estrous cycle can potentially alter reproductive processes (Inskeep, 2004; Wiltbank et al., 2006), in particular reducing the likelihood of pregnancy establishment, and may be linked to divergent reproductive outcomes. Because the corpus luteum is a transient reproductive organ, regression is initially functional and then structural (Sugino and Okuda, 2007). Functional luteal regression is generally characterized by the depletion of progesterone production without structural changes to the corpus luteum, and the timing of functional luteal regression and/or prevention is pivotal for the successful establishment of pregnancy. Embryonic signals must occur by the time luteal regression is initiated to be effective and for pregnancy to be established. In the cow, the critical period is from d 15 to 17 (Thatcher et al., 1986). An area for future research is testing the hypothesis that early luteal regression within subpopulations of normal progesterone profiles are associated with different levels of fertility.

Among the reasons for poor reproductive performance in different strains of Holstein-Friesian cows are poor conception and pregnancy rates rather than a failure to initiate reproductive cycles following calving (Horan et al., 2005; Kolver et al., 2007; Macdonald et al., 2008). With this in mind, NA cows were associated with cluster 3 profile in the current study. These profiles tended to have the lowest plasma progesterone levels on $\mathrm{d} 5$ of the estrous cycle and the latest onset of luteal regression. There is strong evidence that the rise in progesterone early in the estrous cycle has a positive effect on reproductive performance. Mann and Lamming (2001) reported an interaction between plasma progesterone during the early luteal phase of the estrous cycle and the presence of viable embryos. McNeill et al. (2006) reported a linear relationship between
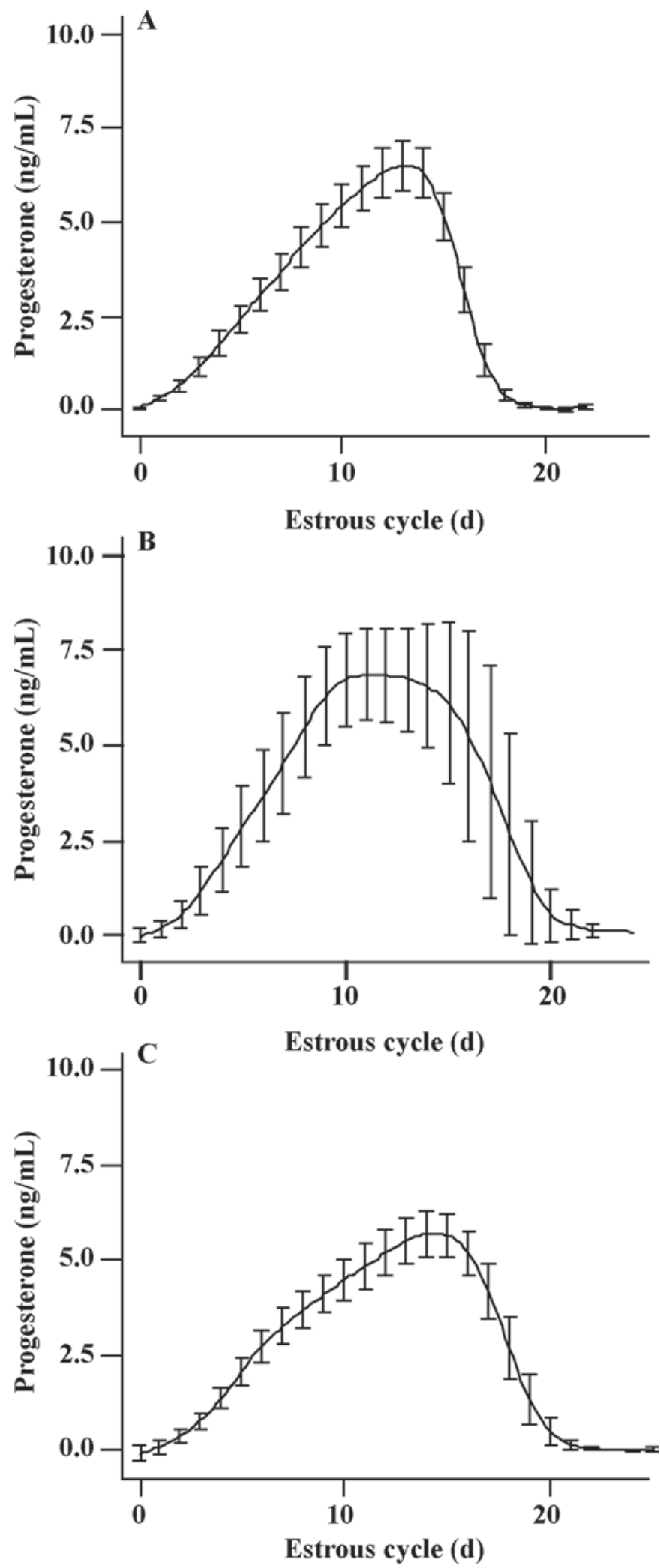

Figure 5. Mean progesterone concentrations $(\mathrm{ng} / \mathrm{mL})$ for each of the subpopulations identified using trait-based clustering: A) cluster 1, peak-like profile, B) cluster 2, flat top-like profile, and C) cluster 3, shows a structured-like profile. 
milk progesterone on d 4 to 6 after ovulation and the probability of embryo survival, confirming a positive association between milk progesterone on d 5 to 7 and pregnancy (Stronge et al., 2005). Mann and Lamming (2001) also reported that elevated progesterone on d 2 to 5 resulted in larger embryos, and that these larger embryos produced more interferon-tau when compared with control cows. Interferon-tau is important in the establishment of pregnancy, embryonic growth, and progesterone concentrations during the early stages of pregnancy; for pregnancy to be successful, a sufficiently large embryo must be present, because the production of interferon-tau is dependent on the size of the embryo (Betteridge et al., 1980; Roberts et al., 1992). Reported differences in progesterone profiles may therefore affect early embryonic growth and, as such, be a factor in differentiating the reproductive success of the different strains.

In this study, there was no association between progesterone profile shape and nutrition, despite the very different feeding systems investigated. This may be the result of the low number of normal profiles evaluated, as feeding level has been reported to affect peripheral progesterone concentrations in both sheep and cattle (Parr et al., 1993a, b; Rabiee et al., 2002; Sangsritavong et al., 2002). Increased DMI increases hepatic blood flow and increases the metabolic clearance rate of progesterone (Rabiee et al., 2002). It has therefore been hypothesized that because DMI increased with genetic selection for milk production, the associated negative effect on progesterone metabolism may be a key contributor to the decline in fertility (Wiltbank et al., 2006). Although the cows on TMR produced more milk and consumed a greater amount of feed (Kolver et al., 2002), there was no evident effect on the progesterone profiles. Rabiee et al. (2002) were similarly unable to establish a relationship between DMI (17.3 and 15.4 $\mathrm{kg}$ ) and plasma progesterone profiles or the excretion of fecal progesterone metabolites.

\section{CONCLUSIONS}

Presented results indicate that subtle changes in progesterone profiles can be identified within otherwise normal estrous cycles, with one clustering technique based on luteal phase empirical features suggesting a genetic difference in profile shape. North American cows exhibited different progesterone profiles than New Zealand cows, consistent with previously reported poorer reproduction in this strain.

\section{ACKNOWLEDGMENTS}

The authors acknowledge the help of both farm and technical staff involved in the collection of samples and 
laboratory analyses. This work was supported by funding from DairyNZ Inc. and the Foundation for Research, Technology, and Science New Zealand.

\section{REFERENCES}

Beam, S. W., and W. R. Butler. 1999. Energy balance, metabolic hormones, and early post-partum follicular development in dairy cows fed prilled lipid. J. Dairy Sci. 81:121-131.

Betteridge, K. J., M. D. Eaglesome, G. C. M. Randall, and D. Mitchell. 1980. Collection, description and transfer of embryos from cattle 10-16 days after oestrus. J. Reprod. Fertil. 59:205-216.

Buckley, F., K. O'Sullivan, J. F. Mee, R. D. Evans, and P. Dillon. 2003. Relationships among milk yield, body condition, cow weight, and reproduction in spring-calved Holstein-Friesians. J. Dairy Sci. 86: 2308-2319.

Everitt, B. S., S. Landau, and M. Leese. 2001. Cluster Analysis, 4th ed. Hodder Arnold, London, UK.

Fahey, J., S. R. Morgan, A. R. Napper, E. S. Kolver, and G. A Verkerk. 2003. A comparative study of ovarian follicle dynamics and IGF-I concentrations during an oestrus cycle in two genotypes of lactating Holstein-Friesian cows, offered pasture or a total mixed ration. Conf. Assoc. Ad. Anim. Breed Genet. 15:68-71.

Friggens, N. C., and M. G. Chagunda. 2005. Prediction of the reproductive status of cattle on the basis of milk progesterone measures: model description. Theriogenology 64:155-190.

Geisert, R. D., G. L. Morgan, E. C. Short Jr., and M. T. Zavy 1992. Endocrine events associated with endometrial function and conceptus development in cattle. Reprod. Fertil. Dev. 4:301-305.

Gould, W. 1993. Resistant nonlinear smoothing using Stata. Stata Tech. Bulletin Reprints ST7-ST12:104-107.

Horan, B., J. F. Mee, P. O'Connor, M. Rath, and P. Dillon. 2005. The effect of strain of Holstein-Friesian cow and feeding system on postpartum ovarian function, animal production and conception rate to first service. Theriogenology 63:950-971.

Inskeep, E. K. 2004. Preovulatory, postovulatory, and postmaternal recognition effects of concentrations of progesterone on embryonic survival in the cow. J. Anim. Sci. 82(E-Suppl 1): E24-E39.

Jones, E., R. Hodgins-Vermaas, H. McCartney, B. Everitt, C. Beech, D. Poynter, I. Palmer, K. Hyams, and S. Wessely. 2002. Postcombat syndromes from the Boer war to the Gulf war: A cluster analysis of their nature and attribution. BMJ 324:321-324.

Kolver, E. S., J. R. Roche, C. R. Burke, J. K. Kay, and P. W. Aspin. 2007. Extending lactation in pasture-based dairy cows: I. Genotype and diet effects on milk and reproduction. J. Dairy Sci. 90:55185530.

Kolver, E. S., J. R. Roche, M. J. de Veth, P. L. Thorne, and A. R. Napper. 2002. Total mixed rations versus pasture diets: Evidence for a genotype $\times$ diet interaction in dairy cow performance. Proc. N.Z. Soc. Anim. Prod. 62:246-251

Macdonald, K. A., G. A. Verkerk, B. S. Thorrold, J. E. Pryce, J. W Penno, L. R. McNaughton, L. J. Burton, J. A. S. Lancaster, J H. Williamson, and C. W. Holmes. 2008. A comparison of three strains of Holstein-Friesian grazed on pasture and managed under different feed allowances. J. Dairy Sci. 91:1693-1707.

Mann, G. E., and G. E. Lamming. 2001. Relationship between maternal endocrine environment, early embryo development and inhibition of the luteolytic mechanism in cows. Reproduction 121:175-180.

McCoy, M. A., S. D. Lennox, C. S. Mayne, W. J. McCaughey, H. W. Edgar, D. C. Catney Jr, M. Verner, D. R. Mackey, and A. W. Gordon. 2006. Milk progesterone profiles and their relationship with fertility, production and disease in dairy cows in Northern Ireland. Anim. Sci. 82:213-222.

McDougall, S., N. B. Williamson, and K. L. Macmillan. 1995. GnRH induces ovulation of a dominant follicle in primiparous dairy cows undergoing anovulatory follicle turnover. Anim. Reprod. Sci. 39:205-214.

McNeill, R. E., M. G. Diskin, J. M. Sreenan, and D. G. Morris. 2006. Association between milk progesterone concentrations on different days and with embryo survival during the early luteal phase in dairy cows. Theriogenology 65:1435-1441.
National Research Council. 2001. Nutrient Requirements of Dairy Cattle, 7th rev. ed. National Academy Press, Washington D.C., USA

Okuda, K., Y. Miyamoto, and D. J. Skarzynski. 2002. Regulation of endometrial prostglandin F2 $\alpha$ synthesis during luteolysis and early pregnancy in cattle. Domest. Anim. Endocrinol. 23:255-264.

Parr, R. A., I. F. Davis, M. A. Miles, and T. J. Squires. 1993a. Feed intake affects metabolic clearance rate of progesterone in sheep. Res. Vet. Sci. 55:306-310.

Parr, R. A., I. F. Davis, M. A. Miles, and T. J. Squires. 1993b. Liver blood flow and metabolic clearance rate of progesterone in sheep. Res. Vet. Sci. 55:311-316.

Petersson, K. J., H. Gustafsson, E. Strandberg, and B. Berglund. 2006. Atypical progesterone profiles and fertility in Swedish dairy cows. J. Dairy Sci. 89:2529-2538.

Rabe-Hesketh, S., and B. Everitt. 2004. Cluster Analysis: Tibetan skulls and air pollution in the USA. Pages 265-283 in A Handbook of Statistical Analyses Using Stata. 3rd ed. Chapman \& Hall/ CRC, London, UK

Rabiee, A. R., D. Dalley, J. M. Borman, K. Macmillan, and F. Schwarzenberger. 2002. Progesterone clearance rate in lactating dairy cows with two levels of dry matter and metabolisable energy intakes. Anim. Reprod. Sci. 72:11-25.

Roberts, R. M., J. C. Cross, and D. W. Leaman. 1992. Interferons as hormones of pregnancy. Endocr. Rev. 13:432-452.

Roche, J. R., D. P. Berry, and E. S. Kolver. 2006. Holstein-Friesian strain and feed effects on milk production, body weight, and body condition score profiles in grazing dairy cows. J. Dairy Sci 89:3532-3543.

Roche, J. R., D. P. Berry, J. M. Lee, K. A. Macdonald, and R. C. Boston. 2007b. Describing the body condition score change between successive calvings: A novel strategy generalizable to diverse cohorts. J. Dairy Sci. 90:4378-4396.

Roche, J. R., K. A. Macdonald, C. R. Burke, and D. P. Berry. 2007a. Associations among body condition, body weight, and reproductive performance in seasonal-calving pasture-based diary cattle. J. Dairy Sci. 90:376-391.

Royal, M. D., A. O. Darwash, A. P. F. Flint, R. Webb, J. A. Woolliams, and G. E. Lamming. 2000. Declining fertility in dairy cattle Changes in traditional and endocrine indices of fertility. Anim. Sci. 70:487-501.

Salgado-Ugarte, I. H., and J. Curtis. 1993. Resistant smoothing using Stata. Stata Tech Bulletin Reprints ST7-ST12:99-103.

Sangsritavong, S., D. K. Combs, R. Sartori, L. E. Armentano, and M. C. Wiltbank. 2002. High feed intake increases liver blood flow and metabolism of progesterone and estradiol-17beta in dairy cattle. J. Dairy Sci. 85:2831-2842.

Silvia, W. J., G. S. Lewis, J. A. McCracken, W. W. Thatcher, and L. Wilson Jr. 1991. Hormonal regulation of uterine secretion of prostaglandin F2 alpha during luteolysis in ruminants. Biol. Reprod. 45:655-663.

Spencer, T. E., and F. W. Bazer. 2002. Biology of progesterone action during pregnancy recognition and maintenance of pregnancy Front. Biosci. 7: d1879-d1898.

Stronge, A. J., J. M. Sreenan, M. G. Diskin, J. F. Mee, D. A. Kenny, and D. G. Morris. 2005. Post-insemination milk progesterone concentrations and embryo survival in dairy cows. Theriogenology 64:1212-1224

Sugino, N., and K. Okuda. 2007. Species-related differences in the mechanism of apoptosis during structural luteolysis. J. Reprod. Dev. 53:977-986.

Thatcher, W. W., F. W. Bazer, D. C. Sharp, and R. M. Roberts. 1986. Interrelationships between uterus and conceptus to maintain corpus luteum function in early pregnancy: sheep, cattle, pigs and horses. J. Anim. Sci. 62(Suppl. 2):25-46.

Wathes, D. C., V. J. Taylor, Z. Cheng, and G. E. Mann. 2003. Follicle growth, corpus luteum function and their effects on embryo development in postpartum dairy cows. Reproduction 61:219-237.

Wiltbank, M., H. Lopez, R. Sartori, S. Sangsritavong, and A. Gumen 2006. Changes in reproductive physiology of lactating dairy cows due to elevated steroid metabolism. Theriogenology 65:17-29. 